\title{
Why do network organizations fail?
}

\author{
Annalisa Tunisini \\ Department of Economic and Business Management Sciences, Universita Cattolica del Sacro Cuore, Milano, Italy, and \\ Michela Marchiori \\ Department of Business Studies, Università degli Studi Roma Tre, Rome, Italy
}

\begin{abstract}
Purpose - The purpose of this paper is to examine network failures and the main reasons why network organizations, intentionally developed by a group of actors to pursue specific goals, become unfruitful and fail in their goals and expectations of creating collective value. The goal of this paper is thus to contribute a better understanding of the reasons network organizations encounter problems in their dynamics that prevent them from reaching the expected outcomes.

Design/methodology/approach - The study is firstly based on a literature review finalized to identify the main variables considered as potentially impacting on network failures. Secondly, the paper is based on a survey conducted on 189 strategic networks that highlighted difficulties in achieving their goals. An analysis of the 24 questionnaires returned generated the results discussed. The empirical study concerns strategic networks intentionally created and signed by Italian SMEs according to a specific law designed to promote the development of inter-firm cooperation ("network contracts").

Findings - The results of the research highlight the role of specific key items related to individual, structural, legitimacy, interaction and governance variables in explaining failures in network organizations. According to the data, failure can occur immediately before the network start-up, resulting in a blocked network or in a subsequent developmental stage, resulting in a dormant network. The empirical research demonstrated that the items affecting network failure differ between blocked and dormant networks. The authors explain such differences, considering them according to the expected goals declared by the two different types of networks.

Originality/value - The question of why networks fail is relevant in times of disruption and digitalization when new forms of organization are needed to link businesses and various stakeholders and thereby develop innovative and sustainable ideas for an entrepreneurial future. However, very few studies have examined network failure. The study contributes to this field of research by investigating the dynamics of networks intentionally developed to reach shared goals. The findings can be useful to both companies that decide to start up a strategic network and the policymakers that promote, finance and monitor inter-firm collaboration.
\end{abstract}

Keywords Strategic networks, Network contract, Network failure, Network organizations, Network pathologies

Paper type Research paper

\section{Introduction}

This paper examines network failures to determine why network organizations, intentionally developed by a group of actors to pursue specific goals, encounter problems and fail to reach these goals and to meet the actors' expectations of creating collective value. The question of why networks fail is relevant in times of disruption and digitalization when new forms of organization are needed to link businesses and various stakeholders to develop innovative and sustainable ideas for an entrepreneurial future.

Research on business and strategic networks, as well as on business-to-business relationships has mostly addressed the structure and dynamics of business networks and the conditions under which networks can positively develop and generate value. A few scholars have studied the burdens of business relationships and interdependencies, focusing on the dark side of business relationships (Snehota and Hakansson, 1995; Anderson and Jap, 2005). Some researchers have examined the

The current issue and full text archive of this journal is available on Emerald Insight at: https://www.emerald.com/insight/0885-8624.htm

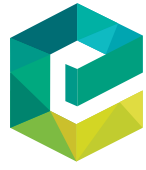

Journal of Business \& Industrial Marketing 35/6 (2020) 1011-1021

Emerald Publishing Limited [ISSN 0885-8624] [DOI 10.1108/JBIM-01-2019-0056] problems emerging in business-to-business interaction relationships to understand how and from where such problems arise, as well as their impact on the wider network (Ford and Havila, 2003). Other scholars have studied the critical issues in the development of business relationships using a relationship lifecycle framework (Johnston and Hausman, 2006; Terawatanavong et al., 2007). Some researchers have underscored the criticism of the start-up stage (Snehota and Hakansson, 1995; Håkansson and Ford, 2002), analyzed the factors that can compromise the continuity of business-tobusiness relationships (Doz, 1996; Arino and de la Torre, 1998) or highlighted the problems and frictions leading to the termination of business relationships (Dwyer et al., 1987;

(C) Annalisa Tunisini and Michela Marchiori. Published by Emerald Publishing Limited. This article is published under the Creative Commons Attribution (CC BY 4.0) licence. Anyone may reproduce, distribute, translate and create derivative works of this article (for both commercial and non-commercial purposes), subject to full attribution to the original publication and authors. The full terms of this licence may be seen at http://creativecommons.org/licences/by/4.0/legalcode

Received 28 January 2019

Revised 11 May 2019

26 July 2019

25 November 2019

Accepted 26 November 2019 
Ellram, 1991), as well as the dynamics underlying the end of the relationships (Havila and Salmi, 2009).

Yet, most of the mentioned studies focus on the negative dynamics of dyadic relationships, with very few studies being conducted at the network level or specifically on the topic of networks failure (Miles and Snow, 1992; Schrank and Whitford, 2011; Sroka and Cygler, 2014a, 2014b; Moretti and Zirpoli, 2016). Our study aims to contribute to the debate in two ways. First, according to network governance approach (Moretti, 2017) we assume the network as the unity of analysis. In particular, we refer to networks strategically designed and developed by small and mid-sized companies to reach collective and shared goals (Gulati et al., 2000; Möller et al., 2005). Our empirical study concerns specifically Italian strategic networks, named network contracts (NCs), created and signed by Italian SMEs according to legal frameworks defined by the Italian Ministry of Economic Development. Second, we adopt a notion of failure related to the problems encountered by a network designed to achieve the goals of the partners.

Thus, this paper seeks to enhance the understanding of why network organizations encounter problems in their dynamics that impede them from reaching the expected outcomes. To this end, our first research question is: what factors hinder a designed network from reaching its expected outcomes? The paper also delves into the various problems that can emerge during a networking start-up and its further development. Consequently, our second research question is: can we envisage different key issues negatively impacting the functioning of the network in its different stages of development?

The paper is organized as follows. First, we review the existing literature on network failure to frame the main variables affecting the failure of a network. Second, we summarize the methodology used to conduct an empirical analysis of Italian NCs and report the results. Such an empirical setting enabled us to develop a discussion on the reasons for the emerging problems hindering the designed network to reach the goals expected and shared by partners at different stages of its development, namely, the start-up phase and the development phase. Finally, we outline our conclusions, define the limits of our study and offer further research suggestions.

\section{Literature review}

Although some studies have examined the problems arising in business related processes and the reasons for the dissolution and termination of dyadic business relationships, very little literature adopting a network level of analysis exists. Moreover, no studies have specifically defined the different problems that business networks might encounter at different stages of their development.

To identify relevant studies, we searched three literature databases (Scopus, Google Scholar and EBSCO) to locate publications on the topic within social psychology, sociology and management literature. To narrow the search to papers of interest to our study, we used the keywords listed in Table I, searching for titles and abstracts. Keywords such as "network failure," "network dissolution," "network pitfalls" and "network pathologies" framed the main variables affecting the failure of a network.

The search results returned a huge number of articles and papers published from 1995 to 2016 in different backgrounds,
Table I Keywords used for literature review

\begin{tabular}{lll}
\hline Network failure & Network dissolution & Network pitfalls \\
Network burdens & Network inertia & Network borders \\
Network collapse & Network crisis & Network conflicts \\
Network pathologies & Network traps & Network dark side \\
\hline
\end{tabular}

including sociological, psychological, managerial, technical, mathematics, medical and IT background. We focused on papers within social psychology, sociology and management fields. To frame this research area, we used the Boolean operator "and" with the added keyword "business." We found only 7 articles that included the keywords in both the title and abstract. Using the references cited by these 7 articles, we also identified another 11 papers relevant to our study. A careful reading of the 18 papers led us to define the detailed variables affecting network dynamics, and in particular, those variables explaining the emerging of problems within business networks. We classified these variables as individual, structural, legitimacy, interaction and governance issues.

With regard to individual issues, Schrank and Whitford (2011, p. 155) defined network failure as "the failure of a more or less idealized set of relational-network institutions to sustain "desirable" activities or to impede "undesirable' activities." According to these authors, the failure of networks, unlike the failure of other organizational forms, depends on the characteristics of the networks' actors. The authors distinguish among different types of failures: network stillbirth or devolution, when networks do not manage to start up because of high opportunisms and ignorance among participants; network involution, which occurs due to high ignorance and competency shortfalls among participants (i.e. missing competences stop the network dynamics); and network contestation when only opportunistic behavior arises. In explaining the reasons underlying standing network failures, the authors focused on actors' individualistic issues referred to as the level of ignorance and competence shortfalls on the one hand and opportunistic behavior on the other hand. Moretti and Zirpoli (2016) also considered two aggregate dimensions causing network failures, both of which refer to the role of individuals (i.e. single actors, personas or organizational group), in the creation and transformation of network ties. The first dimension, framing, refers to how each actor interprets and faces the difficulties to find the best solutions to solve problems. The second dimension, mobilizing, is the process by which the actors converge toward a shared vision and generate coalitions among the actors owning the same interpretative framework.

Sroka and Cygler (2014a, 2014b) examined structural issues. The authors discussed the emergence of network structural pathologies related to the positions of the companies, the density of the network and the choice of links in the network. Balanced or unbalanced power positions among the parties, high or low network densities and open or closed network links can, under different circumstances, act as pathologies generating network failures. Other studies at the sociological level highlight that networks rich in structural holes move information faster and to more people and managers who are not part of the cohesive and embedded networks because they benefit from greater information needed to find new opportunities (Burt, 1992). On the other side, a cohesive 
network can limit the autonomy of the actors, thereby limiting the social ties necessary for cooperation. In summary, network structural features such as density, cohesiveness and the presence or absence of structural holes can be linked to poor network performance (Gargiulo and Benassi, 2000).

Human and Provan (2000) considered the legitimacybuilding process in the network to be a critical issue. According to their study, the reason for the failure of the networks is the failure of legitimacy building both inside and outside the network. For the purposes of this work, it is first necessary to provide a definition of legitimacy for a business network to grasp its importance in the evolutionary process that leads to the success or failure of the network. Human and Provan considered legitimacy to be a generalized perception that the actions and behaviors, as well as the entire structure of the network, are appropriate and desired, thereby guaranteeing credibility both inside and outside the network. This legitimacy turns out to be multidimensional and gives rise to the network as a form, an entity and an interaction. First, the network must be conceived as an organizational form and recognized and accepted as such - initially by internal members and founders and then by those who are outside it. The second dimension concerns an aspect no longer structural but ensures that the network develops as a recognizable identity that allows internal and external subjects to perceive it as a legitimized entity. Finally, legitimacy also concerns the network as interactions, namely, the result of ties and coordination among the members. Only the solid credibility and acceptance of such interactions can guarantee benefits to both the individual company and the whole network. With regard to this latter aspect of legitimacy, the initial conditions of the network formation are particularly relevant (Doz, 1996). The legitimacy-building process of a network as interactions that will guarantee the success of the network originates in this phase and will be directly influenced by the initial cooperation between companies. At this stage, there is still no trust among the potential members, but they recognize all the conditions that will allow the creation of stable links and cooperation.

Referring to these interaction issues, a few recent articles have focused their analysis on the dark side of business interactions (Fang et al., 2011; Grandinetti, 2017). Snehota and Hakansson (1995) highlighted that the existing dark side of business interactions can evolve negatively throughout the network. The perception of high risks in sharing goals and resources can limit the levels of investments in business interactions, thereby negatively impacting the process of value co-creation. Meanwhile, the perception of higher costs whose benefits stem from the business interactions and interdependencies within the network can limit the network performance as well. The indeterminateness of network boundaries can connect actors to unwanted interconnections, especially when it exists in the perception of reputation damages. Conditions of exclusivity in interaction can limit access to new opportunities. The misalignment between the individual and collective strategies can also generate problems in interactions (Zajac and Olsen, 1993) as actors observe and measure a zero-sum game in which the gain of one member will inevitably correspond to the loss of another. Network failures can also relate to the difficulty and resistance in changing or dissolving inter-organizational links to create new ones when the existing ones have become inefficient. This aspect is also known as network inertia (Kim et al., 2006).

In the evolutionary process of a business network, the bonds created can change, and consequently, transform the perception for the companies that originally created them. The impossibility and impediment of modifying these bonds can, over time, prove to be a reason for inefficiency and even failure of the network itself. The first type of constraint to change is internal and is defined in terms of the stability and complexity of the network. Stability concerns the structures, routines and common culture that are sustained over time. Complexity refers to the coexistence within the network of groups with different interests, ideologies and practices; this diversity is amplified as the size of the network increases. Regarding this first level, the inertia for change is strictly connected to the age of the network and its size. Younger networks will be more likely to modify ties that are less rooted, whereas routines and organizational structures created over time often serve to impede change. Similar reasoning can be made with reference to the size of the network; as the number of companies, and therefore, the links that are created increases, it will be more difficult to manage and/or modify them if they are no longer efficient. Network inertia is also influenced by the total volume of involvement of the participating companies in a specific and measurable link, such as in the capital invested for that particular bond and the "multiplexity," that is, the number of roles or relationships that connect the members of the network to each other.

In relation to these issues, one of the few contributions that summarizes network pathologies is and Sroka and Cygler's (2014a, 2014b) paper, which defined three levels of network pathologies as follows: company level (i.e. decline in innovativeness and competitiveness of the single actors, increase of their costs and risks), intra-network level (i.e. competition and/ or opportunistic behavior among network actors) and network level (i.e. decline in network flexibility and competitiveness).

Considering governance issues as reasons for network failures, Provan and Kenis (2008) connected the failure to not having the coordinating skills and task-specific competencies necessary to reach network goals. Some scholars have underscored the lack of shared mechanisms to inhibit opportunism and sustain trust development among members (Hagen and Choe, 1998). Other authors have identified the absence of a network orchestrator as a critical factor without which the network risks failing or being inefficient in creating and delivering value (Dhanaraj and Parkhe, 2006). A network orchestrator is particularly important to enact resource combination and activities' links, guarantee the appropriation of the innovation generated in the network, and reduce the risk of opportunistic behavior. Dhanaraj and Parkhe considered the management of "dynamic stability," namely, the ability of a "hub" company to give legitimacy to the network and avoid friction among members, the formation of isolated groups and the migration to other networks - to be part of the process of orchestrating a network. Such phenomena would lead to the failure of the network itself. Moretti and Zirpoli (2016) concluded that the failure can be due to the lack of representativeness of a network orchestrator capable of inhibiting opportunism, diffusing information and moderating processes. The absence of a network orchestrator, leading to 
ineffective forms of network governance and an inability to guarantee network stability and affective dynamics, can also be a source of failure.

\section{The research}

\subsection{Empirical setting and research methodology}

Our empirical setting for identifying the reasons and dynamics of network failures is represented by 322 NCs. In 2009, the Italian Government introduced a new legislative instrument called the NC to stimulate strategic cooperation among firms to achieve a common goal and constitute a larger organizational form more adept at facing global competition. NC is defined in Article 3, Paragraph 4, Point 3 of Decree no. 5/2009, which was enacted as Law no. 33/2009:

Under the NC, a number of entrepreneurs pursue the aim of increasing, individually and collectively, their innovativeness and competitiveness in the market, and in order to reach this goal, they commit, on the basis of a common network program, to collaborate in well-defined forms and areas related to their business, to exchange industrial, commercial, technical or technological information or services, and to jointly run one or more activities that are covered by the scope of their firms.

The NC is a form of strategic networks (Möller and Rajala, 2007) that can also be depicted as a multi-lateral network (Human and Provan, 2000) that is primarily voluntary in terms of its formation and participation and is promoted by specific legislation developed by the Italian Government (Grundmann et al., 2016). It involves three or more companies (mostly SMEs) and requires an explicit declaration of the general goals to be reached. These goals must refer to the development of an innovative project and/or to internationalization processes. The NC allows the many forms of informal network aggregations to emerge and become objects of financial, legal and fiscal supports by the government. Italian policymakers believe that the introduction of the NC legislation could encourage SMEs' aggregation and offer them a sounder structure for facing the challenges of global innovation and internationalization. The $\mathrm{NC}$ is thus considered a tool for industrial and regional policies (Guercini and Tunisini, 2017a, 2017b) and the network organization forms that derive from it are consistent with what Kilduff and Tsai (2003) referred to as goal-directed rather than serendipitous networks.

From the methodological point of view, we downloaded the list of 2,763 NCs from the website of the Italian Chamber of Commerce in May 2017 (each NC has a specific name and/or brand name). We selected NCs according to the following criteria: first, we focused on NCs categorized in the manufacturing industry because of the need and relevance of SMEs' aggregation to promote Italian industrial competitiveness. Second, we considered NCs formed by more than four companies as a minimum number of actors to enter into network complexities. Third, we considered networks started between 2011 and 2015 because we needed the network to have been operational for a number of years to better enter into its dynamics. The result was $322 \mathrm{NCs}$ formed by 1,864 companies.

In carrying out the empirical survey, we had two requirements:

1 To address the questionnaire to our target (NCs no longer operational or with significant operational problems); and

2 To identify an e-mail address through which to contact the network.
As there are no official sources through which to determine, which NCs in Italy are still operational and working and which are not, the first problem we faced was to identify the criteria for determining which NCs were no longer working (inactive) or dealing with serious operating problems. For each NC, we searched online for the following information, which we assumed to be indicators of the working of the network:

- Analysis of the network website: NC who developed and keep update and improved their websites have been considered working and active;

- Date of the last event organized by the network: no events, the absence of any form of communication of events (showrooms, fairs, exhibitions, conferences, for example) promoted or participated by the NC on the website have been considered indicators of a poor functioning of the network;

- Last news on the website: the absence of any kind of news on the NC (development of products, entering new markets, partnerships, new entrants in the NC, etc.) has been considered as an indicator of difficulties in the working of the network; and

- Network's contact person (i.e. coordinator of the partners' activities as nominated by the partners themselves and formally in charge in the Chamber of Commerce database).

Of the 322 selected NCs, we identified a network contact person for 259 of them. We then examined for each of the 259 NCs the data available on the website and found (Table II):

- 70 NCs registered in the Chamber of Commerce database had a website and were communicating news and events on the web until 2017. We have thus decided to exclude these networks from our detailed analysis as our interest was concentrated to networks showing no activities or to networks with limited or interrupted activities, as their set up; and

- 189 NCs with their own website but no news/events and/ or news/events till 2014 or with no official website; these networks were considered problematic and we decided to address the questionnaire to these networks.

The questionnaire was sent by e-mail to the 189 problematic networks during the second semester of 2017. Section 1 of the questionnaire verified if the 189 networks actually were problematic. Section 2 of the questionnaire identified the specific motivations and goals that the multi-lateral networks originated and the level of achievement of these goals. In our view, these questions were necessary to frame each network, according to our network life-cycle perspective distinguishing between the start-up phase and development phase. Section 3 of the questionnaire sought to identify the variables affecting the network's development. We used a selected number of

Table II Results from the Web analysis of the 259 networks

\begin{tabular}{lll}
\hline & $\begin{array}{l}\text { Networks with activities } \\
(\mathbf{7 0})\end{array}$ & $\begin{array}{l}\text { Problematic networks } \\
(\mathbf{1 8 9})\end{array}$ \\
\hline Website & Yes & Yes \\
News & Yes & No news or news till 2014 \\
Events & Yes & No events or events till 2014 \\
\hline
\end{tabular}


items that could be referred to the five categories of variables identified from the literature (i.e. individual, structural, legitimacy, interaction and governance). Section 3 of the questionnaire used closed questions, where respondents gave their evaluations using a five-point scale. Specifically, the questionnaire examined the following items as negatively affecting network dynamics:

- Individual variables: inability to abandon individualistic mentality, perception of loss of autonomy, opportunistic behaviors, difficulty in foreseeing network results and difficulty in predicting economic returns;

- Structural characteristics of the network: differences in partner characteristics (technological, dimensional and organizational);

- Legitimacy variables: missing support by external resources constituencies (i.e. funders and suppliers);

- Interaction variables: lack of willingness in sharing knowledge, disagreement among companies, lack of active participation by the network partners, difficulty in dissolving the ties borne within the network and changing these ties, absence of any business exchange before the origin of the NC and difficulty in managing partners' relationships; and

- Governance variables: the absence of a network manager and difficulties in coordinating the activities of the network. We also asked about the coordination mechanisms the network firms used and the number of meetings they had held, as the signing of the NC.

The 189 questionnaires were sent to the NC person indicated in the Chamber of Commerce database. This respondent was chosen for our analysis because of his/her general overview of the entire network. We used a Google form platform to deliver the questionnaire and collect information and data. We received 24 responses after 2 recalls during the 2 -month time period, resulting in a 13 per cent response rate. The results of our research are reported in the next subsection.

\subsection{Findings}

Section 1 of the questionnaire used a preliminary question to verify the status of the 189 networks defined as problematic by the desk analysis. We asked the respondents if the network had:

- Activities in progress;

- No activities in progress but some activities have been done in the past and actors are still willing to cooperate; or

- No activities, whether in progress or completed, and an intention to interrupt the joint program.

Of the 24 networks that answered the preliminary question:

- 6 declared that they have activities in progress, so they were classified as active networks;

- 11 declared that they have developed some activities together and currently have no activities in progress, but the actors are willing to continue to cooperate, which we classified as dormant networks and assumed that they had completed the start-up process but encountered problems in the development stage; and

- 7 declared that they had no activity in progress or completed and were going to interrupt the joint program, which we classified as blocked networks and considered them to have identified problems, as the beginning of the start-up phase (Table III).

First, we focused our analysis on the dormant networks (11) and the blocked networks (7). We have also analyzed in detail the answers to the questionnaire given by the 6 networks that declared to be active. Such answers have been summarized in a separate section of the following tables and used to develop comments in comparison with dormant and blocked networks.

The second part of the questionnaire concerned the networks' expected goals in the initial stage. The results identified differences between dormant and blocked networks concerning the number and types of business goals (Tables IV and V). The 6 active networks showed a variety of number of expected goals and also a variety of typology of goals (mostly, go to international markets, develop joint promotional and sales activities, develop innovative products and integrate production phases), while the blocked networks showed a restricted number of goals (one or two goals) and more focalized and ambitious than the dormant networks. In particular, the blocked networks defined goals related to R\&D and new product development projects. Meanwhile, more than half of the dormant networks stated that they wanted to reach at least three goals focused on enabling the partner companies to develop joint promotional activities (63.6 per cent) and expand the range of products or services ( 36.3 per cent); in other words, they sought to use the collaboration to position the companies in the market as part of a wide range of complementary products. The share of sales channel and the realization of $R \& D$ and new project developments were defined at a lower frequency percentage (27.3 per cent). These differences between the two types of networks (i.e. blocked networks focused mostly on $R \& D$ projects while dormant networks finalized predominantly marketing goals) will be useful for discussing the results of the third part of the questionnaire aimed at identifying the variables affecting the functioning of the networks.

Second, in terms of the level of goal achievement, we observed a relevant difference between dormant and blocked networks (Table VI). Dormant networks' responses are aligned with those provided by the active networks. Both highlight a low degree of difficulties encountered in reaching the expected goals, whereas all the blocked networks (except one) claimed to have experienced the impossibility of achieving the expected results during the existence of the network.

Finally, we addressed the variables negatively affecting the networks' functioning. Table VII summarizes the results of our analysis. The table was constructed by calculating the mean and median (the latter showed in parentheses) of the values (from 1 to 5) declared by the respondents for each of the items referencing the five categories of variables (i.e. individual, structural, legitimacy, interaction and governance). The table shows the different results for active, dormant and blocked networks.

The table highlights the items that predominantly negatively impact networks' dynamics. It also indicates, which items have a higher impact on dormant versus blocked networks. Considering our assumptions, we can thus distinguish between those variables and key specific items that create problems impeding the networks' start-up stage versus those that 
Table III Status of the respondent networks

\begin{tabular}{lccc}
\hline & $\begin{array}{c}\text { Active networks (with } \\
\text { activities in progress) }\end{array}$ & $\begin{array}{c}\text { Dormant networks (without any activity Blocked networks (without any activity } \\
\text { in progress but with actors having the } \\
\text { will to cooperate) }\end{array}$ & $\begin{array}{c}\text { in progress and going to interrupt the } \\
\text { joint program) }\end{array}$ \\
\hline Number of networks & 6 & 11 & 7 \\
\hline
\end{tabular}

Table IV Typology of expected goals

\begin{tabular}{lccc}
\hline & Active nets (\%) & Dormant nets (\%) & Blocked nets (\%) \\
\hline Go to international markets & 50 & 18 & 28.6 \\
Jointly access to shared sales channels & 16.6 & 27.3 & 14.3 \\
Joint promotional and sales activities & 50 & 63.6 & 42.8 \\
Develop innovative products and services & 50 & 27.3 & 28.6 \\
Develop R\&D projects & 33.3 & 9 & 57.1 \\
Integrate a few production phases & 50 & 27.3 & 14.3 \\
Share technological information & 16.6 & 36.3 & 28.6 \\
Expand the range of product & 33.3 & 27.3 & - \\
Participate in tenders & - & 9 & - \\
Improve the access to credit & - & - \\
\hline
\end{tabular}

Table V Number of expected goals to reach in the different network typologies

\begin{tabular}{lcccc}
\hline & \multicolumn{4}{c}{ Number of goals to reach } \\
& Up to 2 (\%) & Up to 3 (\%) & Up to 4-5 (\%) & $>\mathbf{5}(\%)$ \\
\hline Active nets & 33.3 & 33.3 & 33.3 & - \\
Dormant nets & 27.3 & 54.5 & 18.2 & - \\
Blocked nets & 71.4 & 14.3 & 14.3 & - \\
\hline
\end{tabular}

Table VI Level of difficulties encountered in the achievement of the expected goals

\begin{tabular}{lccc}
\hline & $\begin{array}{c}\text { Active } \\
\text { nets }\end{array}$ & $\begin{array}{c}\text { Dormant } \\
\text { nets }\end{array}$ & $\begin{array}{c}\text { Blocked } \\
\text { nets }\end{array}$ \\
\hline $\begin{array}{l}\text { Impossibility to reach the goal } \\
\text { (scale 1-5) }\end{array}$ & 2.2 & 2 & 4.3 \\
\hline
\end{tabular}

generate problems during the development stage. We used the responses from the six active networks to compare the different roles of the examined variables and key items in the active and problematic networks. Indeed, Table VII highlights that active networks generally show lower item values than the other networks and this is the first evidence of their better state of health.

As the table highlights, in the case of both blocked and dormant networks, the most impactful role is played by an individual, structural, interaction and governance variables. The legitimacy variables (i.e. missing support by external resources constituencies) neither play a relevant role in determining problems for network success in either the blocked or dormant networks nor do they appear to be important in the case of an active network. The major difficulties experienced by the networks stem from items endogenous to the networks. In other words, respondents did not give relevance to the support and commitment of external institutions and other stakeholders as a distinguishing element for the functioning of the network. Rather, the problems that created obstacles to their functioning related to the actors' behaviors and attitudes, as well as their interactions and interdependencies. Referring to Human and Provan's three levels of legitimacy, it appears that the networks analyzed did not have to face the legitimacy challenges concerning the network as an entity. Rather, the difficulties in building legitimacy in relation to what Human and Provan (2000) called "network-as-interaction" emerged as very relevant. This finding concurs with much of the literature examining business networks, whose positive dynamics are essentially fueled by the linkages of the activities and the resource combination that the actors are capable of enacting through their synergic interactions (Snehota and Hakansson, 1995; Håkansson and Waluszewski, 2007).

In considering the individual variables, the inability to abandon the individualistic mentality and the emerging of opportunistic behavior was particularly relevant for the blocked networks. The shortage of a collective attitude perceived and shown by the actors can explicate why the network encountered problems as early as the start-up phase. Opportunistic behavior is a primary obstacle, especially in the start-up phase of business relationships that lack the necessary trust among the actors as trust is the result of shared experiences (Castaldo, 2007). Regarding the item loss of autonomy, all networks perceived it as not relevant, which was probably due to the specific legal framework of the NC that does not demand strict financial or structural ties to participate in a network. In both blocked and dormant networks, the difficulty in foreseeing network results and the difficulty in predicting economic returns from the network were perceived as problematic items. The latter is also the two individual variables to which the active networks address their attention. This is comprehensible also because the literature on business networks has highlighted that it is always difficult to foresee the results of business relationships because of the 
Table VII Variables and key issues negatively impacting on networks' development

\begin{tabular}{|c|c|c|c|}
\hline & Active & Dormant & Blocked \\
\hline \multicolumn{4}{|l|}{ Individual variables } \\
\hline Inability to abandon individualistic mentality & $2.3(2)$ & $3.3(3)$ & $4.1(5)$ \\
\hline Perception of loss of autonomy & $1.7(1.5)$ & $2.1(2)$ & $1.7(1)$ \\
\hline Opportunistic behavior & $1.66(1.5)$ & $1.7(2)$ & $3(3)$ \\
\hline Difficulty in foreseeing network results & $2.5(3)$ & $3(3)$ & $3.4(4)$ \\
\hline Difficulty in predicting economic returns from the network & $2.5(2.5)$ & $3.4(3.4)$ & $3.4(3.4)$ \\
\hline \multicolumn{4}{|l|}{ Structural variables } \\
\hline $\begin{array}{l}\text { Differences in partner characteristics (technological, } \\
\text { dimensional and organizational) }\end{array}$ & $2.8(3)$ & $2.6(2)$ & $3.7(4)$ \\
\hline \multicolumn{4}{|l|}{ Legitimacy variables } \\
\hline Missing support by external resources constituencies & $1.8(1.5)$ & $2.5(2)$ & $2.2(2)$ \\
\hline \multicolumn{4}{|l|}{ Interaction variables } \\
\hline Lack of willingness in sharing knowledge & $2.16(2)$ & $2.5(3)$ & $3.4(3)$ \\
\hline Disagreement among the companies & $1.5(1)$ & $1.8(2)$ & $3.4(3)$ \\
\hline Lack of active participation by partners & $1.5(2)$ & $3(3)$ & $3.5(4)$ \\
\hline \multicolumn{4}{|l|}{ Difficulty in dissolving the ties borne within the network and to } \\
\hline Absence of any business exchange before the origin of the NC & $4(4)$ & $3.5(3)$ & $3.6(3)$ \\
\hline Difficulty in managing partners' relationships & $1.5(1.8)$ & $2(2.2)$ & $3(3)$ \\
\hline \multicolumn{4}{|l|}{ Governance variables } \\
\hline Difficulties in coordinating the activities & $2.16(2)$ & $2.3(2)$ & $4(4)$ \\
\hline Absence of a network manager & $1.6(1.5)$ & $2.5(2)$ & $2.3(3)$ \\
\hline
\end{tabular}

numerous emerging issues stemming from the interactions and interdependencies that are outside the control of single actors but results of the interaction in itself. Indeed, if networks are established to address environmental uncertainty, the formation of the network itself creates new uncertainties that the network's partners have to address and that are often internal/endogenous in nature (Beckman et al., 2004; Sydow et al., 2013). Although the expected goals were clear in the examined business networks, participants also clearly perceived the difficulties of predicting the outcomes of their interactions with other counterparts. The involved actors were primarily small and mid-sized enterprises, and they considered the difficulty to predict economic returns from initial idiosyncratic investments to be relevant. Active networks also considered the difficulties to foresee results and economic returns as important, but for the latter, this perception is overcome by the positive view of the synergies expected to stem from the joint collective action. These results are consistent with the fact that active networks did not suggest any highly critical issues in the interaction variables.

Considering the interaction variables, in the case of the blocked network, the most relevant items were the disagreement among the companies and the difficulty in managing partners' relationships. It is difficult to envisage the start-up of a business network if partners do not manage to converge to a shared roadmap. Meanwhile, these interaction variables do not play a relevant role for dormant networks as they have experienced the start-up phase and reached some goals. The gap between (good) intentions and interactions becomes evident when there is a need to start the joint action. Disagreements among the partners can stop the process, which is what happened to the blocked networks that also complained about the lack of active participation by partners and the lack of willingness in sharing knowledge. These two items were particularly relevant in the case of dormant networks as well, although they played a frictional role after the network start-up. The absence of any business exchange before the origin of the $N C$ was considered a critical item by all networks, including the active ones. Interestingly, all networks recognized that positive network dynamics are facilitated by preexisting relationship experiences among the partners, which lower the barriers and the timing for mutual understanding, trust, and commitment to interaction. Difficulty in dissolving the ties borne within the network and changing these ties was not considered particularly critical by any of the networks.

Differences in partners' characteristics (technological, dimensional and organizational) were structural variables that created difficulties, particularly for the blocked networks, although active networks also considered them as an obstacle to cooperation. The active networks were formed by fewer participants than the dormant and blocked networks, which likely facilitated the efforts to overcome cultural, managerial and technological differences, but only to a certain degree. In fact, even the active networks indicated that frictions in the networks were generated by dissimilarities among the actors.

In terms of the governance variables, the networks analyzed adopted methods of coordination and control that can be linked to the form of network governance that Provan and Kenis (2008) and Provan et al. (2008) defined as "participant or shared governance" (2008a; 2008b). Shared governance is the most flexible and adaptable form of multilateral networks as it leaves 
autonomy to the organizations involved in the network who try to govern themselves by making all the decisions and manage network activities without the presence of a formal administrative entity. It is the loosest network governance arrangement based on the lean coordination mechanism that aims to nourish the processes of mutual orientation and mutual adaptation among the parties (Gargiulo and Benassi, 1999).

However, according to Provan and Kenis (2008), during its implementation, this form of governance can assume different shapes in terms of the degree of decentralization/centralization of decision-making processes (absence/presence of a leading company that assumes some administrative and coordination activities for the whole network) and the use of formal/informal coordination mechanisms (i.e. regular and planned meetings of designated organizational representatives or intermittent and occasional efforts of those who have a stake in the network's success).

Our analysis also confirmed a variety of modes by which shared governance may be accomplished. Regarding leading firms, only 37.5 per cent of analyzed networks declared their presence in the network organizations (most of them among dormant networks). In terms of the coordination mechanisms, blocked networks used only a few and discontinuous meetings, most of which were organized by actors internal to the networks. The resulting limited opportunities to share knowledge and experiences served as an obstacle to the mutual adaptation processes. On the contrary, active networks experienced varied coordination mechanisms, both formal and informal, and showed a higher number of continuous meetings. Therefore, the blocked networks declared that they had experienced a high level of difficulties in coordinating the activities of their networks, unlike the active and dormant networks, which did not report such difficulties. As other studies have highlighted (Cristofoli et al., 2014), the lack of formalized coordination mechanisms, as well as the absence of a leading company with the role of network administrator may negatively influence network development, hindering blocked networks from moving beyond the start-up phase.

All of the networks declared that it is important for the network success to have a network manager who is external to the network (i.e. not specifically connected to any firm in the network). Only 33.3 per cent of active networks and 27.3 per cent of dormant networks used a network manager. No blocked network leveraged the power of a network manager. However, in general, the absence of a network manager was not perceived as a critical issue, as only five of the dormant and blocked networks considered the absence of a network manager to be a relevant difficulty for their operations. Rather than stressing the difficulties experienced by the absence of a network manager, the analyzed networks converged in recognizing the importance of the "complex and multifaceted" role (Nilsen and Gausdal, 2017) as a facilitator, problem-solver, knowledge broker or innovation orchestrator that a network manager can play, responding to the various needs that arise in the different stages of the network's development.

\section{Discussion}

Our research has distinguished between networks encountering problems, as before the start-up phase (blocked networks) and networks that have passed the start-up phase but have faced problems in further developments (dormant networks). We have sought to explain the reasons underlying the failure of these two forms of networks, namely, failures occurring immediately at the beginning of the network's birth, when the network started up, and in the developmental stage despite a successful start-up. We can explain such differences if we consider the differences in the expected goals declared by the two different types of networks. As already reported, the responses to Section 2 of the questionnaire indicated that blocked networks highlighted a restricted number of more focalized and ambitious goals than dormant networks. In particular, in the blocked networks, the goals concerned R\&D and new product development projects, as well as subsequent sales and promotion of the innovation. The dormant networks showed a larger number and broader set of goals principally addressed to enable partner companies to share sales channels and develop joint promotional activities, especially in the international market. Through the network, each company is also able to make its products part of a larger bouquet of products.

The key aspects affecting the blocked networks and explaining the problems encountered in the start-up stage related to the prevalence of an individualistic approach among the partners and their difficulties to frame the network as a potential source of benefits resulting from their joint activities. Such a situation fueled opportunistic behaviors and limited the adoption of a collective strategy, particularly in the dark side of interactions, thereby generating distrust in the common project. No sharing of knowledge, through either the emerging forms of spontaneous coordination among the parties (for example, by mutual adaptation) or the shared formalized mechanisms of coordination, prevented network start-ups. Rather, the problems could be connected to the ambitious goals of these types of networks. The objectives concerning the development of innovation and $\mathrm{R} \& \mathrm{D}$ management require a great level of cohesiveness, knowledge sharing and belief in the cooperation process among companies. When these elements were missing, as demonstrated by our analysis, the network inevitably failed. The six active networks, on their part, do not complain about the limited knowledge sharing, cohesiveness, loss of autonomy and difficulties in interaction. A collective approach to network strategy has been developed in the active networks despite the fact that they showed a variety of different goals - sales, promotional and innovation goals. Active networks do not complain about any difficulties to reach expected goals, to abandon the individualistic mentality by the partners and problems occurring in interaction. However, it is recognized that cultural, technological and managerial dissimilarities among the partners can obstacle interaction.

Moreover, both in the case of dormant networks and in the active networks, the analysis showed that the difficulties connected to the capability to foresee network results, especially economic returns from the networking process, were perceived as critical issues. The predictability of network results is a critical issue, underlined also by the literature because it is difficult to predict processes and returns stemming from interactions and interdependencies. Moreover, positive returns for some actors of the network do not correspond to the perception of similar positive returns from the perspective of other actors of the same 
network. In the case of the dormant networks the difficulties to foresee network results and to predict economic returns, are consistent with the sales and promotional goals of these networks aimed at generating greater volumes of sales and an increase in market shares. However, the acknowledgment of the market opportunities through a joint action at the international level enabled the companies to overcome the perplexities generated by the unpredictability of the results as they bet on the greater possibilities stemming from the collective action rather than from the individual one. Considering the governance variables, the lack of an external manager was determined to be a weakness because the companies involved in the network need to generate economies of scale and scope in enlarging their markets; an external actor, independent from any of the participating companies, is considered the best coordination mechanism and governance element to synchronize and guide the companies in their joint expansion. Once some joint activities are developed and some sales and promotional goals reached, the dormant networks could survive for some time while stopping their development. However, they also declared that they considered networking to be a positive process and that they were ready to try a new network start-up. A network's shift to the developmental stage probably demands an external promoter and activator capable of proving effective economic returns from the network and to keep the companies aligned and focused on their new various shared goals. Meanwhile, the innovation goals that characterize the blocked networks require a mechanism of coordination internal to the networks themselves; in particular, it is important that companies spontaneously interconnect and adapt, having a strong belief in their joint innovative projects. This is stressed by the active networks whose coordination mechanisms are mostly based on the continuous meeting, spontaneous interaction and mutual adaptation pressed by the strong belief in the shared goals. The absence of an internal commitment to the network stops it during the start-up stage.

Our analysis indicated that external legitimacy variables, defined as missing support by external resources constituencies, do not appear particularly relevant, whereas internal legitimacy items assume a relevant role in conditioning the network's evolution. Government financial support is not considered a relevant condition for continuing the network's organization. Institutional stakeholders' (e.g. Chamber of Commerce) acknowledgment, support and commitment, as well as those of suppliers and customers, were found to be less relevant than internal legitimacy (i.e. partner companies' reciprocal acknowledgment of the power of networking), probably for two reasons. First, a network's functioning is connected to the will and belief of the network actors. Business interactions create value if and when actors connect activities and combine resources, developing "cooperative interaction" (Provan et al., 2008). The evidence of the benefits from the collective strategic actions represents the most important contribution to building internal legitimacy. Thus, networks first need to be legitimized by their members, as this internal legitimacy pushes networks' partners to strongly engage in cooperative interaction. Second, external legitimacy is considered most critical at a more advanced stage of the network lifecycle, when the network organization has acquired a stronger position in the market and needs to reinforce its own specific identity in the eyes of customers, as well as be legitimized by constituencies as an entity in its own right ("network as an entity"). Once the network has conquered its own market autonomy, external legitimation can provide great support in enabling the network to realize its full potential.

\section{Conclusions, limitations and further research}

The article examined networks' failure to develop a better understanding of why network organizations encounter problems in their dynamics, and thus, fail to reach their expected outcomes. A number of variables discussed in the literature as the main determinants of network failure were analyzed and discussed, and our empirical research helped us identify a number of key aspects affecting the functioning of the network. Through our research, we also distinguished between two types of failure, thereby identifying dormant networks and blocked networks. Our analysis made it possible to highlight the different impacts that the key items have on these two types of networks. We then interpreted and discussed the results of our analysis by connecting them to the goals that motivated the establishment of the networks.

Our findings can be useful both to companies that decide to start up a strategic network, specifically a NC under the framework of the Italian law and to policymakers who promote, finance and monitor the development of inter-firm collaborations through business networks. In fact, the functionality of business networks will be an essential success criterion for companies in addressing the challenges of our time that need a more flexible and faster business strategy. However, our study is not without limitations. The main limitation is the limited number of responses to the questionnaire, meaning our analysis relied on data from only a few respondents. Although the responses provided much quantitative and qualitative information, a greater number of replies could further support and develop our line of reasoning. In addition, our assumptions in defining problematic networks should be validated by additional specific questions finalized to capture more sophisticated variables defining and explaining the stage of the network lifecycle. Finally, we interviewed only one person per network. On the one side, we have identified and selected these respondents because of their role that let them have a general and extensive overview of their network and its ongoing history, as well as mutual expected goals and their level of achievement. On the other side, we know that it could be more effective to get the perspectives of other network participants - at least one from each partner company. This further analysis could be developed by targeting a limited number of networks. The research can thus be considered a preliminary step to further in-depth investigations to provide a more detailed definition of the status of the network and a deeper analysis of the role played by specific variables that appear more neglected at the moment (e.g. structural and governance variables). A more extensive survey could also better explain the variety of interplay among different variables in determining the failure of a network. 


\section{References}

Anderson, E. and Jap, S. (2005), "The dark side of close relationships", MIT Sloan Management Review, Vol. No. 3, pp. $75-82$.

Arino, A. and De La Torre, J. (1998), "Learning from failure: towards an evolutionary model of collaborative ventures", Organization Science, Vol. 9 No. 3, pp. 306-325.

Beckman, C.M., Haunschild, P.R. and Phillips, D.J. (2004), "Friends or strangers? Firm-specific uncertainty, market uncertainty, and network partner selection", Organization Science, Vol. 15 No. 3, pp. 259-275.

Burt, R.S. (1992), Structural Holes: The Social Structure of Competition, Harvard University Press, Cambridge, MA.

Castaldo, S. (2007), Trust in Market Relationships, Edward Elgar Publishing, Cheltenham.

Cristofoli, D., Markovic, J. and Meneguzzo, M. (2014), "Governance, management and performance in public networks: how to be successful in shared-governance networks", Fournal of Management \& Governance, Vol. 18 No. 1, pp. 77-93.

Dhanaraj, C. and Parkhe, A. (2006), "Orchestrating innovation networks", Academy of Management Review, Vol. 31 No. 3, pp. 659 -669.

Doz, Y.L. (1996), "The evolution of cooperation in strategic alliances: initial conditions or learning processes?”, Strategic Management fournal, Vol. 17 No. S1, pp. 55-83.

Dwyer, R., Schurr, P.H. and Oh, S. (1987), "Developing buyer-seller relationships", fournal of Marketing, Vol. 51 No. 2, pp. 11-27.

Ellram, L.M. (1991), "Life-cycle patterns in industrial buyer-seller partnerships", International fournal of Physical Distribution \& Logistics Management, Vol. 21 No. 9, pp. 12-21.

Fang, S.R., Chang, Y.S. and Peng, Y.C. (2011), "Dark side of relationships: a tensions-based view", Industrial Marketing Management, Vol. 40 No. 5, pp. 774-784.

Ford, D. and Havila, V. (2003), "Problems in relationships: when it all goes wrong", 19th Annual IMP Conference, Lugano, September, pp. 4-6.

Gargiulo, M. and Benassi, M. (1999), "The dark side of social capital", in Leenders, R., Gabbay, R. (Eds), Corporate Social Capital and Liability, Springer Science + Business Media, New York, NY.

Gargiulo, M. and Benassi, M. (2000), "Trapped in your own net? Network cohesion, structural holes, and the adaptation of social capital”, Organization Science, Vol. 11 No. 2, pp. 183-196.

Grandinetti, R. (2017), "Exploring the dark side of cooperative buyer-seller relationships", Fournal of Business \& Industrial Marketing, Vol. 32 No. 2, pp. 326-336.

Grundmann, S., Cafaggi, F. and Vettori, G. (Eds) (2016), The Organizational Contract: From Exchange to Long-Term Network Cooperation in European Contract Law, Routledge, New York, NY.

Guercini, S. and Tunisini, A. (2017a), "Formalizing in business networks as a tool for industrial policy", IMP fournal, Vol. 11 No. 1, pp. 91-108.

Guercini, S. and Tunisini, A. (2017b), "Regional development policies", in Hakansson, H., Snehota, I. (Eds), No Business is an Island: Making Sense of an Interactive Business World, Emerald Publishing, Bingley, pp. 141-155.

Gulati, R., Nohria, N. and Zaheer, A. (2000), "Strategic networks", Strategic Management fournal, Vol. 21 No. 3, pp. 203-215.

Håkansson, H. and Ford, D. (2002), "How should companies interact in business networks?", fournal of Business Research, Vol. 55 No. 2, pp. 133-139.

Håkansson, H. and Snehota, I. (1995), "The burden of relationships or who's next", in Turnbull, P W., Yorke, D., Naudé, P. (Eds), IMP Conference (11th): Interaction, Relationships And Networks: Past - Present - Future, 07-09 September; Manchester Federal School of Business and Management, Manchester.

Håkansson, H. and Waluszewski, A. (Eds) (2007), Knowledge and Innovation in Business and Industry: The Importance of Using Others, Routledge, New York, NY.

Havila, V. and Salmi, A. (2009), Managing Project Ending, Routledge, New York, NY.

Human, S.E. and Provan, K.G. (2000), "Legitimacy building in the evolution of Small-Firm multliateral networks: a comparative study of success and demise", Administrative Science Quarterly, Vol. 45 No. 2, pp. 327 -365.

Johnston, W.J. and Hausman, A. (2006), "Expanding the marriage metaphor in understanding long-term business relationships", Fournal of Business $\mathcal{E}$ Industrial Marketing, Vol. 21 No. 7, pp. 446-452.

Kilduff, M. and Tsai, W. (2003), Social Networks and Organizations, Sage, London.

Kim, T.Y., Oh, H. and Swaminathan, A. (2006), "Framing interorganizational network change: a network inertia perspective", Academy of Management Review, Vol. 31 No. 3, pp. 704-720.

Miles, R.E. and Snow, C.C. (1992), "Causes of failure in network organizations", California Management Review, Vol. 34 No. 4, pp. $53-72$.

Möller, K. and Rajala, A. (2007), "Rise of strategic nets - new modes of value creation", Industrial Marketing Management, Vol. 36 No. 7, pp. 895-908.

Möller, K., Rajala, A. and Svahn, S. (2005), "Strategic business nets - their type and management", fournal of Business Research, Vol. 58 No. 9, pp. 1274-1284.

Moretti, A. (2017), The Network Organization: A Governance Perspective on Structure, Dynamics and Performance, Palgrave Macmillan, London.

Moretti, A. and Zirpoli, F. (2016), "A dynamic theory of network failure: the case of the Venice film festival and the local hospitality system", Organization Studies, Vol. 37 No. 5, pp. 607-633.

Nilsen, E.R. and Gausdal, A.H. (2017), "The multifaceted role of the network orchestrator - a longitudinal case study", International foumal of Innovation Management, Vol. 21 No. 6.

Provan, K.G. and Kenis, P. (2008), "Modes of network governance: structure, management, and effectiveness", Fournal of Public Administration Research and Theory, Vol. 18 No. 2, pp. 229 -252.

Provan, K.G., Kenis, P., Human, S.E., (2008), "Legitimacy building in organizational networks", in Blomgren Bingham, L. and O'Leary, R. (Eds), Big Ideas in 
Collaborative Public Management, Routledge, New York, NY, pp. 121-137.

Schrank, A. and Whitford, J. (2011), "The anatomy of network failure", Sociological Theory, Vol. 29 No. 3, pp. 151-177.

Snehota, I. and Hakansson, H. (Eds) (1995), Developing Relationships in Business Networks, Routledge, London.

Sroka, W. and Cygler, J. (2014a), "Pathologies in interorganizational networks", Procedia Economics and Finance, Vol. 12, pp. 626-635.

Sroka, W. and Cygler, J. (2014b), "Structural pathologies in inter-organizational networks and their consequences", Procedia - Social and Behavioral Sciences, pp. 52-63.

Sydow, J., Müller-Seitz, G. and Provan, K.G. (2013), "Managing uncertainty in alliances and networks-from governance to practice", in Das T.K. (Ed.), Managing Knowledge in Strategic Alliances, IAP, Greenwood Conn, pp. 1-43.

Terawatanavong, C., Whitwell, G.J. and Widing, R.E. (2007), "Buyer satisfaction with relational exchange across the relationship lifecycle", European Fournal of Marketing, Vol. 41 Nos 7/8, pp. 915-938.

Zajac, E.J. and Olsen, C.P. (1993), "From transaction cost to transactional value analysis: implications for the study of interorganizational strategies", fournal of Management Studies, Vol. 30 No. 1, pp. 131-145.

\section{Further readings}

Della Corte, V. and Aria, M. (2014), "Why strategic networks often fail: some empirical evidence from the area of Naples", Tourism Management, Vol. 54, pp. 3-15.

Gausdal, A.H. and Nilsen, E.R. (2011), "Orchestrating innovative SME networks: the case of 'HealthInnovation'", Fournal of the Knowledge Economy, Vol. 2 No. 4, pp. 586-600.

Grandori, A. and Soda, G. (1995), "Interfirm network: antecedents, mechanisms and firms", Organization Studies, Vol. 16 No. 2, pp. 183 -214.

Hurmelinna-Laukkanen, P. and Nätti, S. (2012), "Network orchestrator and knowledge mobility in innovation networks", fournal of Business and Management, Vol. 4, pp. 244-264.

\section{Corresponding author}

Annalisa Tunisini can be contacted at: annalisa.tunisini@, unicatt.it

For instructions on how to order reprints of this article, please visit our website:

www.emeraldgrouppublishing.com/licensing/reprints.htm

Or contact us for further details: permissions@emeraldinsight.com 